\title{
Allometric Models to Predicate Single-Tree Biomass in the Eurasian Larix spp. Forest
}

\author{
Vladimir Andreevich Usoltsev ${ }^{1,2}$, Seyed Omid Reza Shobari ${ }^{*}$, Ivan Stepanovich Tsepordey ${ }^{2}$, \\ Walery Zukow ${ }^{3}$
}

${ }^{1}$ Ural State Forest Engineering University, 620100 Yekaterinburg, Sibirskiy Trakt, 37, Russia

${ }^{2}$ Botanical Garden of Ural Branch of RAS, 620144 Yekaterinburg, str. 8 Marta, 202a, Russia

${ }^{3}$ Faculty of Earth Sciences and Spatial Management, Nicolaus Copernicus University, Lwowska 1 str., 87-100 Toruń, Poland

*corresponding author’s e-mail: Omidshobeyri214@gmail.com

Received: 21 March 2020 / Accepted: 15 June 2020

\begin{abstract}
Today, estimating of biological productivity or carbon-depositing ability of forests is going on the global level, and its increase is one of the major factors of climate stabilization. In recent years, two trends in the harmonization of allometric models of tree biomass have been developing. The first of them is related to ensuring the additivity of the biomass component composition, and the second one - to the search for the so-called generic model applicable to a wide range of environmental conditions. However, all "pseudo-generic" models give significant biases in their application in local conditions. In our modeling, we adhere to the principle of biomass additivity, split "generic" model into regional variants by introducing dummy variables, and build the model at the transcontinental level for the first time. When using the unique in terms of the volume of database of trees of the genus Larix Mill. In a number of 420 sample trees, the trans-Eurasian additive allometric models of biomass of trees for Eurasian larch forests are developed, and thereby the combined problem of model additivity and generality is solved. The additive model of tree biomass of Larix is harmonized in two ways: it eliminated the internal contradictions of the component and the total biomass equations, and in addition, it takes into account regional differences of trees of equal sizes on their biomass, i.e. it reflects the regional peculiarities of the component structure of tree biomass.
\end{abstract}

Key words: genus Larix, equations additivity, biosphere role of forests, biomass of singletrees, allometric models, sample plots, biological productivity, transcontinental tables of biomass.

\section{Introduction}

Study of biosphere role and climate conditionality of biological productivity of world forest is one of the most priority directions of ecology and biogeography sciences. It is known that changes in the vegetation cover of Eurasia occur both in the latitudinal direction due to changes in the solar radiation (Grigoriev \& Budyko, 1956), and in the meridional direction due to changes in the continental climate (Komarov, 1921). Therefore, models of the biomass of trees and stands have been developed, including their mass-forming indices as independent variables, as well as indices of natural zoning and climate continentality (Usoltsev et al., 2018). 
Due to current climate changes, priority is given to changes in the biomass of forest ecosystems under the influence of average temperatures and precipitation (Usoltsev et al., 2019a, 2019b; Hubau et al., 2020). Since these predictive models reflect long-term adaptive responses of stands to regional climate conditions, but do not take into account rapid trends of current changes, they are considered to be preliminary (Usoltsev et al., 2019b).

Along with biomass models that take into account both the natural zoning and continental climate, as well as temperature and precipitation, models and taxation standards for estimating biomass distributed by geographical regions are necessary for practical purposes. Generic allometric models only work well for aboveground biomass without component differentiating, mainly in tropical forests (Chave et al., 2001). However, when assessing the regional component composition of biomass, such models give biases (Usoltsev et al., 2017). Modern methods of modelling the biological productivity of single-trees and forest stands are developed in terms of biomass component additivity (Bi et al., 2010; Dong et al., 2015) and the transition from "pseudo-generic" allometric models to really generic, supposing regionalization of biomass model by introducing dummy variables ( $\mathrm{Fu}$ et al., 2012). The database of single-tree biomass compiled for forest-forming species in Eurasia (Usoltsev, 2016) has enabled these modern methodologies to begin modelling additive tree biomass on transcontinental level.

In this article, an attempt to develop additive allometric models of single-tree biomass of one of the most common species in Eurasia - larch (Larix spp.). These models will provide the basis for the development of regional transcontinental standards for estimating tree and forest stand biomass and its temporal changes using the traditional forest mensuration and inventories.

\section{Materials and methods}

Of the mentioned database the materials in a number of 420 sample trees of four vicarage species of the genus Larix are taken, that are distributed in eight eco-regions and marked respectively by eight dummy variables from $X_{0}$ to $X_{7}$ (Table 1 ). The distribution of sample plots, on which sample trees are taken in different ecoregions of Eurasia, is shown in Figure 1. 
Table 1 . The scheme of regional coding actual biomass of 420 sample trees by dummy variables

\begin{tabular}{|c|c|c|c|c|c|c|c|c|c|c|c|}
\hline \multirow{2}{*}{ Region* } & \multirow{2}{*}{$\begin{array}{c}\text { Species** of } \\
\text { Larix }\end{array}$} & \multicolumn{7}{|c|}{ Dummy variables } & \multirow{2}{*}{$\begin{array}{l}\text { Range of } \\
\mathrm{DBH}, \mathrm{cm}\end{array}$} & \multirow{2}{*}{\begin{tabular}{|c} 
Range of \\
tree height, \\
m
\end{tabular}} & \multirow{2}{*}{$\begin{array}{c}\text { Number of } \\
\text { measure- } \\
\text { ments }\end{array}$} \\
\hline & & $X_{1}$ & $X_{2}$ & $X_{3}$ & $X_{4}$ & $X_{5}$ & $X_{6}$ & $X_{7}$ & & & \\
\hline WME & L. decidua Mill. & 0 & 0 & 0 & 0 & 0 & 0 & 0 & $7.1 \div 47.8$ & $9.8 \div 34.0$ & 14 \\
\hline$\overline{E R}$ & L. sibirica Ledeb. & 1 & 0 & 0 & 0 & 0 & 0 & 0 & $1.0 \div 35.0$ & $2.3 \div 28.0$ & 25 \\
\hline Tst & L. sibirica Ledeb. & 0 & 1 & 0 & 0 & 0 & 0 & 0 & $6.2 \div 28.0$ & $7.9 \div 17.8$ & 28 \\
\hline WSn & $\begin{array}{l}\text { L. sibirica Ledeb.; } \\
\text { L. gmelinii (Rupr.) } \\
\text { Kuzen. }\end{array}$ & 0 & 0 & 1 & 0 & 0 & 0 & 0 & $2.1 \div 38.0$ & $2.9 \div 24.8$ & 116 \\
\hline ESn & $\begin{array}{l}\text { L. gmelinii (Rupr.) } \\
\text { Kuzen. }\end{array}$ & 0 & 0 & 0 & 1 & 0 & 0 & 0 & $0.3 \div 22.7$ & $1.4 \div 14.8$ & 66 \\
\hline FEn & $\begin{array}{l}\text { L. gmelinii (Rupr.) } \\
\text { Kuzen. }\end{array}$ & 0 & 0 & 0 & 0 & 1 & 0 & 0 & $3.9 \div 52.8$ & $2.9 \div 30.0$ & 43 \\
\hline Ch & $\begin{array}{l}\text { L. sibirica Ledeb.; } \\
\text { L. gmelinii Rupr. } \\
\text { Kuzen. }\end{array}$ & 0 & 0 & 0 & 0 & 0 & 1 & 0 & $0.5 \div 31.0$ & $1.5 \div 24.3$ & 50 \\
\hline Jap & $\begin{array}{l}\text { L. kaempferi (Lamb.) } \\
\text { Carrière }\end{array}$ & 0 & 0 & 0 & 0 & 0 & 0 & 1 & $4.0 \div 35.9$ & $4.3 \div 26.7$ & 73 \\
\hline
\end{tabular}

*Region designations: WME - West and Middle Europe; ER - European part of Russia, Central territory; Tst - Turgay steppe; WSn - Western Siberia, northern taiga; ESn - Eastern Siberia, Northern taiga; FEn - Far East, northern taiga; Ch - Northeast China; Jap - Japanese islands.

** According to World Flora Online, An Outline Flora of All Known Plants (WFO, 2020) Larix sukaczewii Dylis is synonym of $L$. sibirica Ledeb.; L. cajanderi Mayr is synonym of L. gmelinii (Rupr.) Kuzen.; and L. leptolepis (Siebold \& Zucc.) Gordon is synonym of L. kaempferi (Lamb.) Carrière.

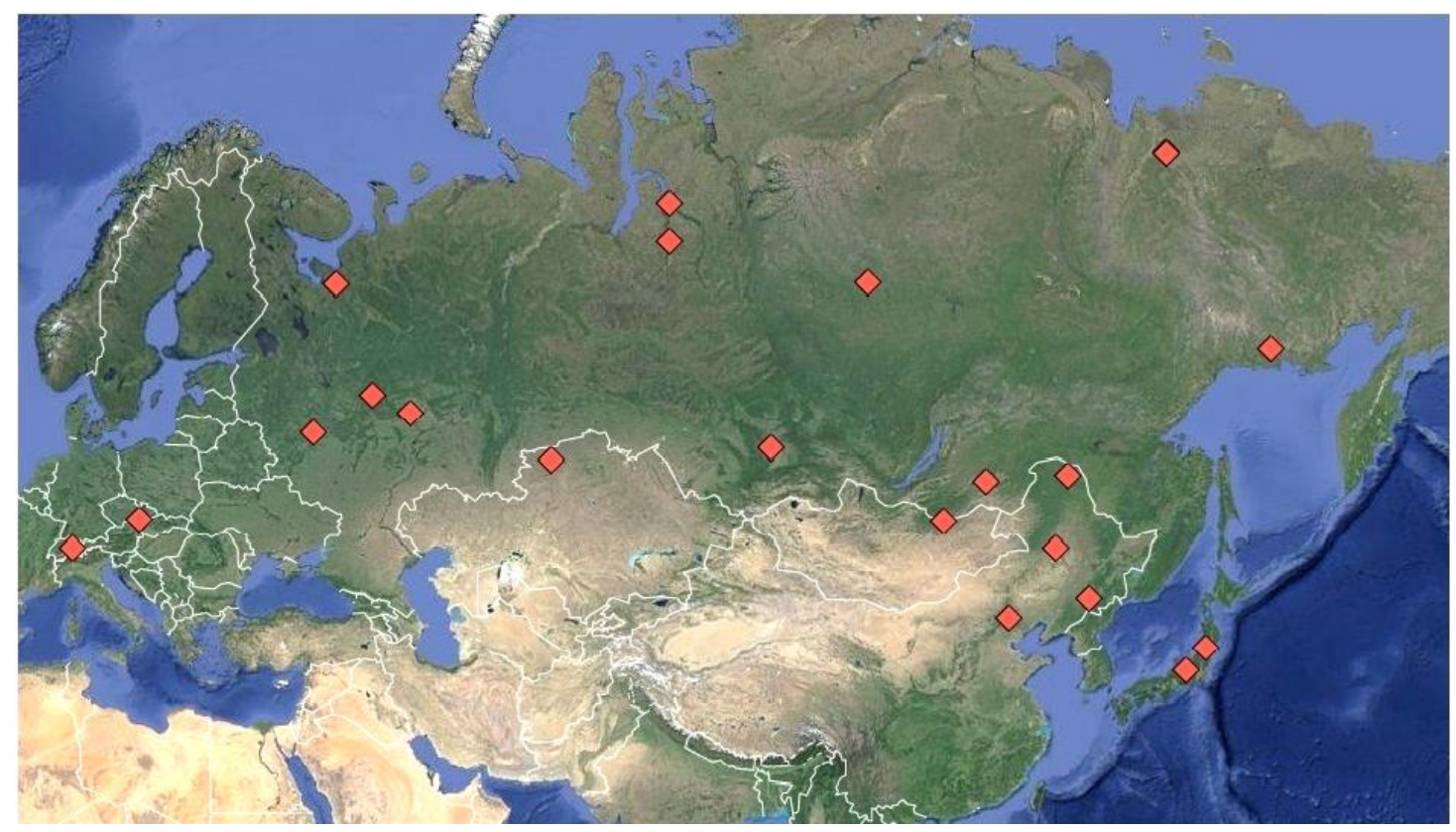


Figure 1. The distribution of sample plots, on which sample trees are taken in different ecoregions of Eurasia

According to the structure of disaggregating three-step additive model system (Tang et al., 2000; Dong et al., 2015), total biomass, estimated by the total equation, exploded into components according to the scheme presented in Figure 2. The coefficients of the regression models for all three steps are evaluated simultaneously, which ensures additivity of the all components: total, intermediate and initial ones (Dong et al., 2015).

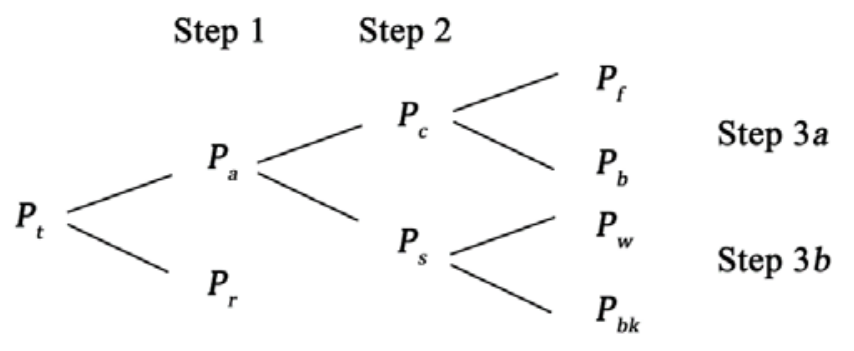

Figure 2. The pattern of disaggregating three-step proportional weighting additive model. Designation: $P_{t}, P_{r}, P_{a}, P_{c}, P_{s}, P_{f}, P_{b}, P_{w}$ and $P_{b k}$ are tree biomass respectively: total, underground (roots), aboveground, crown (needles and branches), stems above bark (wood and bark), needles, branches, stem wood and stem bark correspondingly, kg.

\section{Results and discussion}

Initial allometric models are calculated:

$$
\ln P_{i}=a_{i}+b_{i}(\ln D)+c_{i}(\ln H)+d_{i}(\ln D)(\ln H)+\Sigma g_{i j} X_{j},
$$

where $P_{i}$-biomass of $i$-th component, kg; $D$ - diameter on breast height, $\mathrm{cm} ; H$ - tree height, $\mathrm{m} ; i$ - index of biomass component: total $(t)$, aboveground $(a)$, roots $(r)$, tree crown $(c)$, stem above bark (s), foliage (f), branches $(b)$, stem wood (w) and stem bark (bk); $j$ - index (code) of dummy variable, from 0 to 7 (see Table 1). $\Sigma g_{i j} X_{j}$ - block of dummy variables for $i$-th biomass component of $j$-th ecoregion. Model (1) after antilogarithmic procedure has the form:

$$
P_{i}=e^{a i} D^{b i} H^{c i} D^{d i(\ln H)} e^{\Sigma g i j X j}
$$

Rationale for the structure of the regression model (1) was made earlier (Usoltsev et al., 2017). Since calculation of regression coefficients in the model (1) is made in the transformed data, to eliminate biases caused by logarithmic modification of variables, in the equation the amendment proposed by G.L. Baskerville (1972) is introduced. Using the programme of common regression analysis the calculation of coefficients of equations (1) is performed and their characteristic is obtained, that is given in the Table 2 after correcting the logarithmic transformation by G.L. Baskerville (1972) and bringing it to the form (2). All the 
regression coefficients for numerical variables of the equations (2) are significant at the level of probability of 0.95 or higher, and the equations are adequate to empirical data.

By substituting the regression coefficients of initial equations from Table 2 into the structure of the additive model, presented in Table 3, when using three-step scheme of proportional weighting, we got transcontinental additive model of component composition of larch tree biomass of double harmonization, the final appearance of which is given in Table 4 . The model is valid in the range of actual data of height and diameter of the sample trees shown in the Table 1.

By tabulating the model obtained (Table 4) according to the given values of $D$ and $H$ as well as by the values of the dummy variables, localizing the general model for eco-regions, you can calculate regional transcontinental standards for Eurasia, intended for estimating tree and forest additive biomass components.

Because sometimes it is impossible to measure the height of trees in sample plots, for such cases when calculating the biomass per ha the auxiliary equation intended for using the proposed model (2) is calculated:

$$
\begin{aligned}
& H=2.387 D^{0.7114} \mathrm{e}^{0.1649 / D} \mathrm{e}^{-0.1886 X 1} \mathrm{e}^{-0.1254 X} \mathrm{e}^{-0.1644 X 3} \mathrm{e}^{-0.4100 X 4} \mathrm{e}^{-0.2704 X 5} \mathrm{e}^{-0.2219 X 6} \mathrm{e}^{-0.2346 X} ; \\
& \operatorname{adj} R^{2}=0.918 .
\end{aligned}
$$

Variable (1/D) introduced in the structure of the model (3) for correction of allometry, biased in small trees due to the shift of diameter $D$ in the upper part of tree crown. Tabulating of built additive models (2) in Excel format is fulfilled. Because the volume of tables obtained can exceed the format of journal article, we are limit ourselves to some regional characteristics analysis of the structure of biomass of trees of the same size when using the fragment of summary table for larch (Table 5). In their analysis, you can see that the maximum values for total biomass of equal trees occur in Western (82 kg) and Eastern (74-98 kg) parts of the studied area, that are under the influence of a humid climate of the Atlantic and Pacific oceans, respectively. From the Atlantic coast to the eastern direction, on the territory of European Russia and in Turgai Depression the total tree biomass is reduced to 55-62 kg. But in the subzone of northern taiga in Siberia the total tree biomass increases up to $82-110 \mathrm{~kg}$ due to the low density of standing trees in the permafrost. Approximately the same regional patterns are inherent and for aboveground biomass.

It was found (Cunia \& Briggs, 1984; Reed \& Green, 1985), that the correction of internal inconsistency of biomass equations by ensuring their additivity does not necessarily means improvements in the accuracy of biomass estimating, it is necessary to ascertain, 
whether adequate the additive model obtained and how its adequacy characteristics are related to the same indices of independent (trivial) equations? 
Table 2. The characteristic of independent allometric equations for larch trees

\begin{tabular}{|c|c|c|c|c|c|c|c|c|c|c|c|c|}
\hline $\begin{array}{l}\text { Biomass } \\
\text { compone }\end{array}$ & \multicolumn{11}{|c|}{ Independent variables and the model regression coefficients } & \multirow{2}{*}{$\begin{array}{r}\operatorname{adj} R^{2 *} \\
0.987\end{array}$} \\
\hline$P_{t}$ & 0.2342 & $D^{1.5672}$ & $H^{0.4054}$ & $D^{0.0931(\ln H)}$ & $e^{-0.3963 X 1}$ & $e^{-0.2728 X 2}$ & $e^{0.0016 X 3}$ & $e^{0.1681 X 4}$ & $e^{0.3002 X 5}$ & $e^{0.1786 X 6}$ & $e^{-0.1001 X 7}$ & \\
\hline \multicolumn{13}{|c|}{ Step 1} \\
\hline$P_{a}$ & 0.1832 & $D^{1.4212}$ & $H^{0.3134}$ & $D^{0.1841(\ln H)}$ & $e^{-0.1885 X 1}$ & $e^{-0.0747 X 2}$ & $e^{-0.1639 X 3}$ & $e^{0.1857 \times 4}$ & $e^{-0.0631 X 5}$ & $e^{-0.0947 X 6}$ & $e^{-0.1221 X 7}$ & 0.991 \\
\hline$P_{r}$ & 0.0383 & $D^{1.9268}$ & $H^{0.1825}$ & $D^{0.0308(\ln H)}$ & $e^{-0.6254 X 1}$ & $e^{0.0191 X 2}$ & $e^{-0.3614 X 3}$ & $e^{0.4929 X 4}$ & $e^{1.2546 X 5}$ & $e^{1.1750 X 6}$ & $e^{0.2900 X 7}$ & 0.954 \\
\hline \multicolumn{13}{|c|}{ Step 2} \\
\hline$P_{c}$ & 0.5341 & $D^{2.2312}$ & $H^{-1.7550}$ & $D^{0.2494(\ln H)}$ & $e^{-0.1750 X 1}$ & $e^{-0.3032 X 2}$ & $e^{-0.5668 \times 3}$ & $e^{-0.3290 X 4}$ & $e^{-0.2613 X 5}$ & $e^{-0.3483 \times 6}$ & $e^{-0.1243 X 7}$ & 0.904 \\
\hline$P_{s}$ & 0.0804 & $D^{1.3238}$ & $H^{0.6898}$ & $D^{0.1700(\ln H)}$ & $e^{-0.2019 X 1}$ & $e^{-0.0271 X 2}$ & $e^{-0.0833 X 3}$ & $e^{0.2779 X 4}$ & $e^{-0.0286 X 5}$ & $e^{-0.0654 X 6}$ & $e^{-0.1733 X 7}$ & 0.992 \\
\hline \multicolumn{13}{|c|}{ Step 3a } \\
\hline$P_{f}$ & 0.1032 & $D^{2.0986}$ & $H^{-1.5553}$ & $D^{0.1874(\ln H)}$ & $e^{0.3966 X 1}$ & $e^{0.1968 X 2}$ & $e^{-0.1623 X 3}$ & $e^{0.0686 X 4}$ & $e^{-0.0193 X 5}$ & $e^{0.0847 X 6}$ & $e^{0.3110 X 7}$ & 0.855 \\
\hline$P_{b}$ & 0.3662 & $D^{2.3314}$ & $H^{-1.7586}$ & $D^{0.2438(\ln H)}$ & $e^{-0.3327 X 1}$ & $e^{-0.4231 X 2}$ & $e^{-0.6662 X 3}$ & $e^{-0.3923 X 4}$ & $e^{-0.3125 X 5}$ & $e^{-0.4403 X 6}$ & $e^{-0.2260 X 7}$ & 0.908 \\
\hline \multicolumn{13}{|c|}{ Step 3b } \\
\hline$P_{w}$ & 0.0487 & $D^{1.3125}$ & $H^{0.7886}$ & $D^{0.1730(\ln H)}$ & $e^{-0.1860 X 1}$ & $e^{0.0454 X 2}$ & $e^{-0.0218 X 3}$ & $e^{0.3077 X 4}$ & $e^{0.0332 X 5}$ & $e^{-0.0282 X 6}$ & $e^{0.0050 X 7}$ & 0.993 \\
\hline$P_{b k}$ & 0.0304 & $D^{1.3274}$ & $H^{0.1312}$ & $D^{0.2344(\ln H)}$ & $e^{-0.2909 X 1}$ & $e^{0.1207 X 2}$ & $e^{0.1761 X 3}$ & $e^{0.6553 X 4}$ & $e^{-0.2840 X 5}$ & $e^{0.2626 X 6}$ & $e^{0.2783 X 7}$ & 0.978 \\
\hline
\end{tabular}

* $\operatorname{adj} R^{2}$ - adjusted coefficient of determination. 
Table 3. The structure of three-step additive models obtained by proportional weighting. Symbols here and further see in equation (1)

\begin{tabular}{|c|c|}
\hline \multirow{2}{*}{ Step 1} & $P_{r}=\frac{1}{1+\frac{a_{a} D^{b_{a}} H^{c_{a}} D^{d_{a}(\ln H)} e^{\Sigma e_{a j} X_{j}}}{a_{r} D^{b_{r}} H^{c_{r}} D^{d_{r}(\ln H)} e^{\sum e_{r j} X_{j}}}} \times P_{t}$ \\
\hline & $P_{a}=\frac{1}{1+\frac{a_{r} D^{b_{r}} H^{c_{r}} D^{d_{r}(\ln H)} e^{\Sigma e_{r j} X_{j}}}{a_{a} D^{b_{a}} H^{c_{a}} D^{d_{a}(\ln H)} e^{\Sigma e_{a j} X_{j}}}} \times P_{t}$ \\
\hline \multirow[t]{2}{*}{ Step 2} & 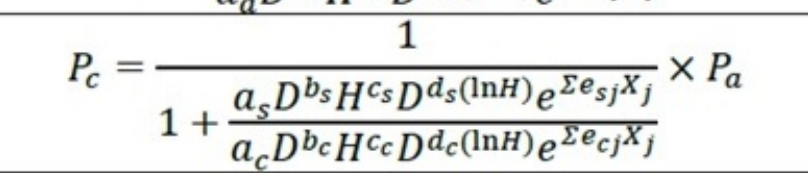 \\
\hline & $P_{s}=\frac{1}{1+\frac{a_{c} D^{b_{c}} H^{c_{c}} D^{d_{c}(\ln H)} e^{\Sigma e_{c j} X_{j}}}{a_{s} D^{b_{s}} H^{c_{s}} D^{d_{s}(\ln H)} e^{\Sigma e_{s j} X_{j}}}} \times P_{a}$ \\
\hline \multirow[t]{2}{*}{ Step $3 a$} & $P_{f}=\frac{1}{1+\frac{a_{b} D^{b_{b}} H^{c_{b}} D^{d_{b}(\ln H)} e^{\Sigma e_{b j} X_{j}}}{a_{f} D^{b_{f}} H^{c_{f}} D^{d_{f}(\ln H)} e^{\Sigma e_{f j} X_{j}}}} \times P_{c}$ \\
\hline & $P_{b}=\frac{1}{1+\frac{a_{f} D^{b_{f}} H^{c_{f}} D^{d_{f}(\ln H)} e^{\Sigma e_{f j} X_{j}}}{a_{b} D^{b_{b}} H^{c_{b}} D^{d_{b}(\ln H)} e^{\Sigma e_{b j} X_{j}}}} \times P_{c}$ \\
\hline \multirow[t]{2}{*}{ Step $3 b$} & $P_{w}=\frac{1}{1+\frac{a_{b k} D^{b_{b k}} H^{c_{b k}} D^{d_{b k}(\ln H)} e^{\Sigma e_{b k j} X_{j}}}{a_{w} D^{b_{w}} H^{c_{w}} D^{d_{w}(\ln H)} e^{\Sigma e_{w j} X_{j}}}} \times P_{s}$ \\
\hline & $P_{b k}=\frac{1}{1+\frac{a_{w} D^{b_{w}} H^{c_{w}} D^{d_{w}(\ln H)} e^{\sum e_{w j} X_{j}}}{a_{b k} D^{b_{b k}} H^{c_{b k}} D^{d_{b k}(\ln H)} e^{\sum e_{b k j} X_{j}}}} \times P_{s}$ \\
\hline
\end{tabular}


Table 4. Three-step additive model of component biomass composition for larch trees, obtained by proportional weighing

\begin{tabular}{|c|c|}
\hline \multicolumn{2}{|c|}{$P t=0.2342 D^{1.5672} H^{0.4054} D^{0.0931(\ln H)} e^{-0.3963 X 1} e^{-0.2728 X 2} e^{0.0016 X 3} e^{0.1681 X 4} e^{0.3002 X 5} e^{0.1786 X 6} e^{-0.1001 X 7}$} \\
\hline Step 1 & $P a=\frac{1}{1+0.2093 D^{0.5056} H^{-0.1309} D^{-0.1532(\ln H)} e^{-0.4369 X 1} e^{0.0938 X 2} e^{-0.1975 X 3} e^{0.3072 X 4} e^{1.3177 X 5} e^{1.2697 X 6} e^{0.4121 X 7}} \times P t$ \\
\cline { 2 - 3 } & $P r=\frac{1}{1+4.7775 D^{-0.5056} H^{0.1309} D^{0.1532(\ln H)} e^{0.4369 X 1} e^{-0.0938 X 2} e^{0.1975 X 3} e^{-0.3072 X 4} e^{-1.3177 X 5} e^{-1.2697 X 6} e^{-0.4121 X 7}} \times P t$ \\
\hline Step 2 & $P c=\frac{1}{1+0.1505 D^{-0.9074} H^{2.4448} D^{-0.0794(\ln H)} e^{-0.0269 X 1} e^{0.2760 X 2} e^{0.4836 X 3} e^{0.6069 X 4} e^{0.2327 X 5} e^{0.2829 X 6} e^{-0.0489 X 7}} \times P a$ \\
\cline { 2 - 3 } & $P s=\frac{1}{1+6.6460 D^{0.9074} H^{-2.4448} D^{0.0794(\ln H)} e^{0.0269 X 1} e^{-0.2760 X 2} e^{-0.4836 X 3} e^{-0.6069 X 4} e^{-0.2327 X 5} e^{-0.2829 X 6} e^{0.0489 X 7}} \times P a$ \\
\hline Step 3a & $P f=\frac{1}{1+3.5479 D^{0.2328} H^{-0.2033} D^{0.0565(\ln H)} e^{-0.7293 X 1} e^{-0.6199 X 2} e^{-0.5040 X 3} e^{-0.4609 X 4} e^{-0.2932 X 5} e^{-0.5250 X 6} e^{-0.5370 X 7}} \times P C$ \\
\cline { 2 - 3 } & $P b=\frac{1}{1+0.2819 D^{-0.2328} H^{0.2033} D^{-0.0565(\ln H)} e^{0.7293 X 1} e^{0.6199 X 2} e^{0.5040 X 3} e^{0.4609 X 4} e^{0.2932 X 5} e^{0.5250 X 6} e^{0.5370 X 7}} \times P c$ \\
\hline Step 3b & $P w=\frac{1}{1+0.6248 D^{0.0150} H^{-0.6574} D^{0.0614(\ln H)} e^{-0.1049 X 1} e^{0.0753 X 2} e^{0.1978 X 3} e^{0.3476 X 4} e^{-0.3172 X 5} e^{0.2908 X 6} e^{0.2733 X 7}} \times P s$ \\
\cline { 2 - 3 } & $P b k=\frac{1}{1+1.6005 D^{-0.0150} H^{0.6574} D^{-0.0614(\ln H)} e^{0.1049 X 1} e^{-0.0753 X 2} e^{-0.1978 X 3} e^{-0.3476 X 4} e^{0.3172 X 5} e^{-0.2908 X 6} e^{-0.2733 X 7} \times P s}$ \\
\hline
\end{tabular}


Table 5. Fragments of the table of additive tree biomass for diameter $14 \mathrm{~cm}$ and tree height of $14 \mathrm{~m}$ according to the eco-regions and corresponding species of the genus Larix

\begin{tabular}{|c|c|c|c|c|c|c|c|c|}
\hline $\begin{array}{c}\text { Biomass } \\
\text { component }\end{array}$ & \multicolumn{8}{|c|}{ Eco-regions and corresponding species of the genus Larix } \\
\hline Total biomass & 81.65 & 54.93 & 62.15 & 81.78 & 96.59 & 110.24 & 97.62 & 73.87 \\
\hline Roots & 13.24 & 6.10 & 10.90 & 11.21 & 20.12 & 46.25 & 39.82 & 16.70 \\
\hline Aboveground & 68.41 & 48.83 & 51.26 & 70.57 & 76.47 & 63.99 & 57.80 & 57.16 \\
\hline Foliage & 1.70 & 2.22 & 1.66 & 1.75 & 1.64 & 1.67 & 1.73 & 2.29 \\
\hline Branches & 9.69 & 6.09 & 5.08 & 5.99 & 5.87 & 7.08 & 5.83 & 7.62 \\
\hline Stem above bark & 57.01 & 40.52 & 44.51 & 62.83 & 68.96 & 55.24 & 50.23 & 47.25 \\
\hline Stem wood & 48.49 & 34.98 & 37.42 & 51.74 & 55.22 & 48.97 & 40.67 & 38.38 \\
\hline
\end{tabular}


Table 6. The characteristics of "methodized" independent allometric equations for larch trees

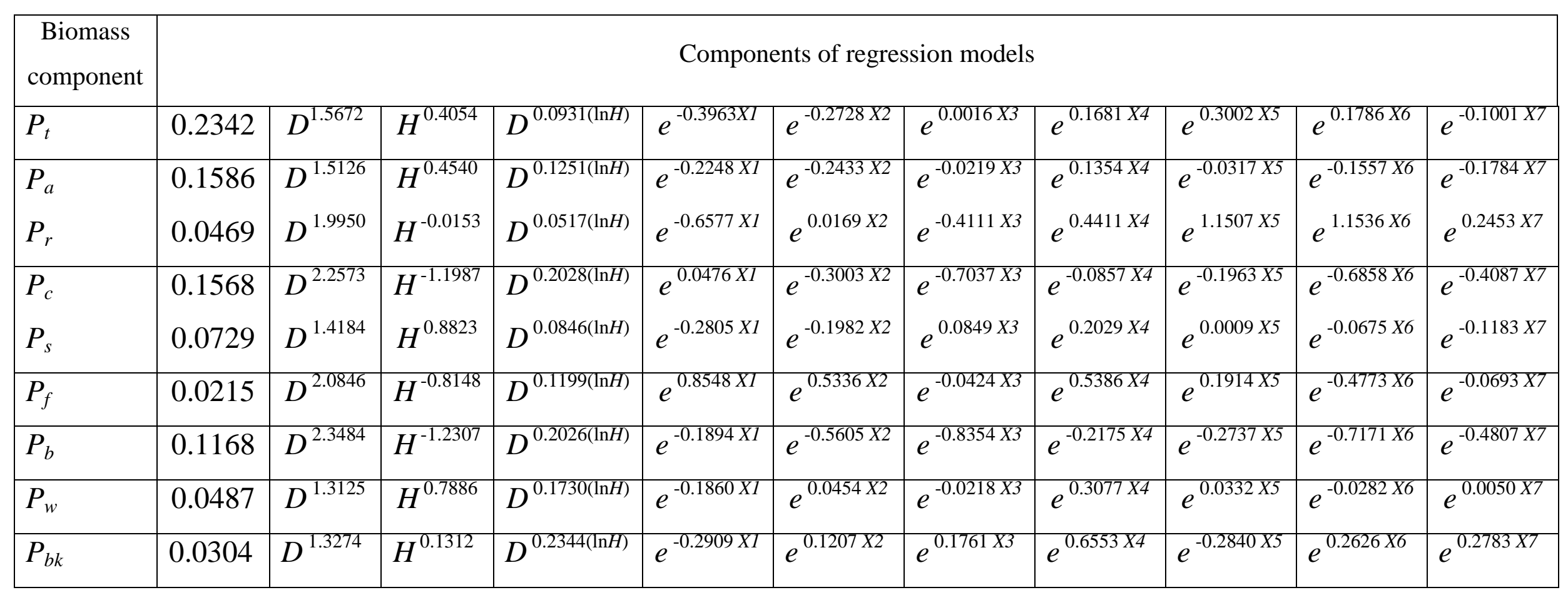


To this purpose, the estimates of biomass obtained from independent and additive equations are compared with actual biomass values by calculating the coefficient of determination $R^{2}$ calculated by the formula:

$$
R^{2}=1-\frac{\sum_{i=1}^{N}\left(Y_{i}-\widehat{Y}_{i}\right)^{2}}{\sum_{i=1}^{N}\left(Y_{i}-\bar{Y}\right)^{2}},
$$

where $Y_{i}$ - actual biomass values; $\hat{Y}_{i}$ - predicted biomass values; $\bar{Y}$ - the mean actual value of all $(N)$ trees.

To properly compare the adequacy of independent and additive equations, we reproduce the original data in a comparable condition, i.e. independent equations for all components of biomass are calculated according to the same data that the additive ones and the equations for the total biomass. Description of such "methodized" equations is given in the Table 6. The results of the comparison (Table 7) indicate that while additive equations internally consistent, but compared to the independent equations they have better characteristics of adequacy not for all component biomass.

The ratio of actual values and derived ones by tabulating independent and additive tree biomass models (Fig. 3) shows the degree of correlativeness of the actual and calculated values and, in many cases, the absence of visible differences in the structure of residual variances obtained on two named models. More or less the value of $R^{2}$ of one or the other model is determined by the random position of actual values of biomass of largest trees in confidence range and uneven dispersion, namely accidental because of their small number and the greatest contribution to the residual variance (see Fig. 3).

Table 7. Comparison of the adequacy indices of the independent and additive equations for larch tree biomass

\begin{tabular}{|c|c|c|c|c|c|c|c|c|c|c|}
\hline \begin{tabular}{c} 
Adequacy $\begin{array}{c}\text { Biomass components* } \\
\text { index }\end{array}$ \\
\cline { 2 - 8 }
\end{tabular} & $P t$ & $P a$ & $P r$ & $P s$ & $P w$ & $P b k$ & $P c$ & $P b$ & $P f$ \\
\hline \multicolumn{8}{|c|}{ Independent equations } \\
\hline$R^{2}$ & 0.975 & 0.973 & $\mathbf{0 . 8 5 2}$ & $\mathbf{0 . 9 2 8}$ & $\mathbf{0 . 9 2 1}$ & 0.956 & $\mathbf{0 . 6 1 3}$ & $\mathbf{0 . 5 8 5}$ & $\mathbf{0 . 6 2 4}$ \\
\hline \multicolumn{8}{|c|}{ Additive equations } \\
\hline$R^{2}$ & 0.975 & 0.967 & $\mathbf{0 . 8 9 1}$ & $\mathbf{0 . 9 8 5}$ & $\mathbf{0 . 9 6 5}$ & 0.907 & $\mathbf{0 . 7 4 9}$ & $\mathbf{0 . 7 3 7}$ & $\mathbf{0 . 7 2 1}$ \\
\hline
\end{tabular}

*Designations see Figure 2. Bold components, for which $R^{2}$ values of the additive models higher than independent ones. 

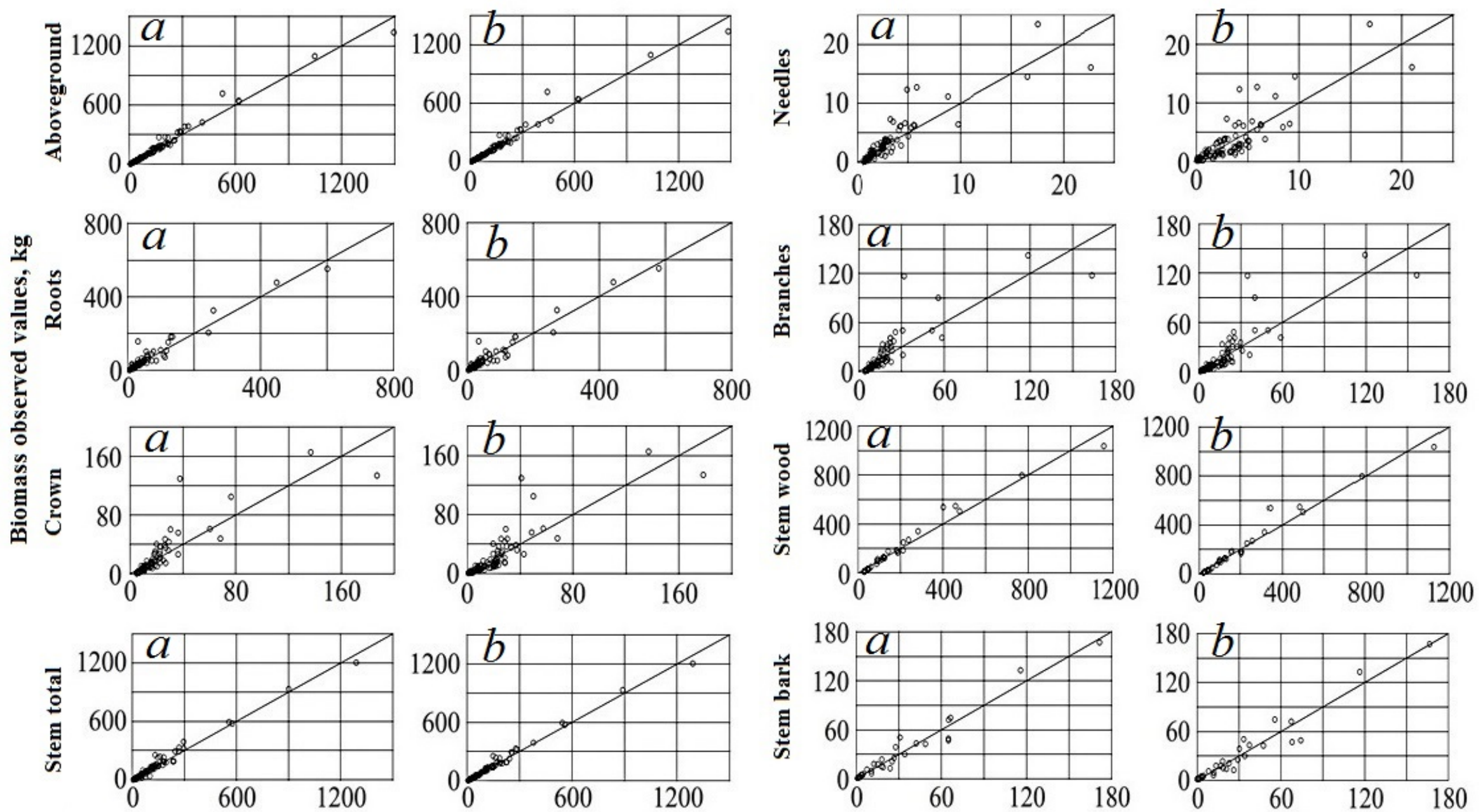

Figure 3. The ratio of observed values and the values derived by calculation of independent (a) and additive (b) models of tree biomass 


\section{Conclusions}

When using the unique in terms of the volumes of databases on the levels of a single-tree of the genus Larix, the trans-Eurasian additive allometric models of biomass of trees for Eurasian larch forests are developed for the first time, and thereby the combined problem of model additivity and generality is solved. The additive model of tree biomass of Larix is harmonized in two ways: it eliminated the internal contradictions of the component and the total biomass equations, and in addition, it takes into account regional differences of trees of equal sizes on their biomass, i.e. it reflects the regional peculiarities of the component structure of tree biomass. The proposed model and corresponding tables for estimating tree biomass makes them possible to calculate larch stand biomass ( $t / \mathrm{ha})$ on Eurasian forests when using measuring taxation.

\section{Acknowledgments}

We thank the anonymous referees for their useful suggestions. This paper is fulfilled according to the programs of current scientific research of the Ural Forest Engineering University and Botanical Garden of the Ural Branch of Russian Academy of Sciences.

\section{References}

Baskerville G.L., 1972, Use of logarithmic regression in the estimation of plant biomass. Canadian Journal of Forest Research 2: 49-53.

Bi H., Long Y., Turner J., Lei Y., Snowdon P., Li Y., Harper R., Zerihun A. \& Ximenes F., 2010, Additive prediction of aboveground biomass for Pinus radiata (D. Don) plantations. Forest Ecology and Management 259: 2301-2314.

Chave J., Riera B. \& Dubois M.A., 2001, Estimation of biomass in a neotropical forest of French Guiana: spatial and temporal variability. Journal of Tropical Ecology 17: 7996.

Cunia T. \& Briggs R.D., 1984, Forcing additivity of biomass tables: some empirical results. Canadian Journal of Forest Research 14: 376-384.

Dong L., Zhang L. \& Li F., 2015, A three-step proportional weighting system of nonlinear biomass equations. Forest Science 61(1): 35-45.

Fu L.Y., Zeng W.S., Tang S.Z., Sharma R.P. \& Li H.K., 2012, Using linear mixed model and dummy variable model approaches to construct compatible single-tree biomass equations at different scales - A case study for Masson pine in Southern China. Journal of Forest Science 58(3): 101-115.

Grigoriev A.A. \& Budyko M.I., 1956, On the periodic law of geographical zoning. Doklady Akadimii Nauk SSSR 110(1): 129-132.

Hubau W., Lewis S.L., Phillips O.L., Affum-Baffoe K., Beeckman H., Cuní-Sanchez A., Daniels A.K., Ewango C.E.N., Fauset S., Mukinzi J.M., Sheil D., Sonké B., Sullivan M.J.P., Sunderland T.C.H., Taedoumg H., Thomas S.C., White L.J.T., Abernethy K.A., Adu-Bredu S., Amani C.A., Baker T.R., Banin L.F., Baya F., Begne S.K., Bennett A.C., Benedet F., Bitariho R., Bocko Y.E., Boeckx P., Boundja P., Brienen R.J.W., Brncic T., Chezeaux E., Chuyong G.B., Clark C.J., Collins M., Comiskey J.A., Coomes D.A., Dargie G.C., de Haulleville T., Kamdem M.N.D., Doucet J.L., 
Esquivel-Muelbert A., Feldpausch T.R., Fofanah A., Foli E.G., Gilpin M., Gloor E., Gonmadje C., Gourlet-Fleury S., Hall J.S., Hamilton A.C., Harris D.J., Hart T.B., Hockemba M.B.N., Hladik A., Ifo S.A., Jeffery K.J., Jucker T., Yakusu E.K., Kearsley E., Kenfack D., Koch A., Leal M.E., Levesley A., Lindsell J.A., Lisingo J., LopezGonzalez G., Lovett J.C., Makana J.R., Malhi Y., Marshall A.R., Martin J., Martin E.H., Mbayu F.M., Medjibe V.P., Mihindou V., Mitchard E.T.A., Moore S., Munishi P.K.T., Bengone N.N., Ojo L., Ondo F.E., Peh K.S., Pickavance G.C., Poulsen A.D., Poulsen J.R., Qie L., Reitsma J., Rovero F., Swaine M.D., Talbot J., Taplin J., Taylor D.M., Thomas D.W., Toirambe B., Mukendi J.T., Tuagben D., Umunay P.M., van der Heijden G.M.F., Verbeeck H., Vleminckx J., Willcock S., Wöll H., Woods J.T. \&, Zemagho L., 2020, Asynchronous carbon sink saturation in African and Amazonian tropical forests. Nature 579: 1-27.

Komarov V.L., 1921, Meridional'naya zonal'nost' organizmov (Meridional zonality of organisms), Dnevnik I vserossiiskogo sezda russkikh botanikov v Petrograde (Diary of the 1st All-Russian Congress of Russian botanists in Petrograd) 3: 27-28.

Reed D.D. \& Green E.J., 1985, A method of forcing additivity of biomass tables when using nonlinear models. Canadian Journal of Forest Research 15: 1184-1187.

Tang S., Zhang H. \& Xu H., 2000, Study on establish and estimate method of compatible biomass model. Scientia Silvae Sinica 36: 19-27 (in Chinese with English abstract).

Usoltsev V.A., 2016, Single-tree biomass of forest-forming species in Eurasia: database, climate-related geography, weight tables. Ural State Forest Engineering University, Yekaterinburg, 336 pp. http://elar.usfeu.ru/handle/123456789/5696

Usoltsev V.A., Kolchin K.V. \& Voronov M.P., 2017, Dummy variables and biases of allometric models when local estimating tree biomass (on an example of Picea L.). Еко-potencial 1(17): 22-39. http://elar.usfeu.ru/bitstream/123456789/6502/1/eko-1702.pdf

Usoltsev V.A., Shobairi S.O.R. \& Chasovskikh V.P., 2018, Geographic gradients of forest biomass of two needled pines on the territory of Eurasia. Ecological Questions 29 (2): 9-17.

Usoltsev V.A., Zukow W., Osmirko A.A., Tsepordey I.S. \& Chasovskikh V.P., 2019a, Additive biomass models for Larix spp. single-trees sensitive to temperature and precipitation in Eurasia. Ecological Questions 30(2): 57-67.

Usoltsev V.A., Zukow W., Osmirko A.A., Tsepordey I.S., Chasovskikh V.P., 2019b, Additive biomass models for Quercus spp. single-trees sensitive to temperature and precipitation in Eurasia. Ecological Questions 30 (4): 29-40.

WFO, 2020,World Flora Online. Published on the Internet. http://www.worldfloraonline.org [Accessed: 16 May 2020] 